\title{
Estudio comparativo de sistemas de sujeción de una placa antidesgaste utilizada en chutes de transferencia usando simulación numérica
}

Rosendo Franco', Herbert Yepez ${ }^{1}$, Julio M. Ramírez¹, y Joel J. Sandoval²

(1) Grupo INACOM/Aula PUCP-CIMNE, Sección Ing. Mecánica, Dpto. de Ingeniería, Pontificia Universidad Católica del Perú, Av. Universitaria 1801, Lima 32-Perú. (correo-e: rofranco@pucp.edu.pe; hyepez@pucp.pe; julio.ramirezs@pucp.pe)

(2) Fundición Ferrosa S.A.C., Calle Los Árboles Mz. B Lote 5, Urb. Huerto Santa Lucía, Lima 03-Perú.

(correo-e: joel.sandoval@fundicionferrosa.com.pe)

Recibido Ene. 2, 2020; Aceptado Mar. 5, 2020; Versión final Mar. 30, 2020, Publicado Ago. 2020

\begin{abstract}
Resumen
Se presenta un estudio comparativo entre dos alternativas de diseño del sistema de sujeción de una placa antidesgaste utilizada en chutes de transferencia de la industria minera. El estudio consiste en el análisis del comportamiento mecánico del sistema de sujeción, considerando la influencia del espesor de la placa antidesgaste. Para este propósito, se usa simulación numérica de elementos finitos, incluyendo su validación experimental. Los resultados revelan que la placa antidesgaste puede alcanzar un espesor remanente de 7.5 $\mathrm{mm}$ en la alternativa 1 y $12 \mathrm{~mm}$ en la alternativa 2, considerando un factor de seguridad de 1.5 . Ambas alternativas muestran un mejor desempeño que el diseño actual, donde la placa antidesgaste se retira con un espesor de $15 \mathrm{~mm}$ debido a las limitaciones del sistema de sujeción. Se concluye que la alternativa 1 es la mejor propuesta ya que permite alargar la vida útil de la placa antidesgaste en un $20 \%$.
\end{abstract}

Palabras clave: placa antidesgaste; chute de transferencia; sistema de sujeción; simulación numérica

\section{Comparative study of fastening systems of an anti-wear plate used in transfer chutes by means numerical simulation}

\begin{abstract}
This research article presents a comparative study between two design alternatives of an anti-wear plate fastening system used in transfer chutes of the mining industry. The mechanical behavior of the fastening system is analyzed while considering the influence of the anti-wear plate thickness. For this purpose, finite element numerical simulation is used, including its experimental validation. The results reveal that the antiwear plate can reach a remaining thickness of $7.5 \mathrm{~mm}$ in alternative 1 and $12 \mathrm{~mm}$ in alternative 2, considering a safety factor of 1.5 . Both alternatives perform better than the current design available, where the anti-wear plate is removed with a thickness of $15 \mathrm{~mm}$ due to fastening system limitations. It is concluded that alternative 1 is the best option proposed here since it allows to extending the life of the anti-wear plate by $20 \%$.
\end{abstract}

Keywords: anti-wear plate; transfer chute; fastening system; numerical simulation 


\section{INTRODUCCIÓN}

La industria minera busca mantener en óptimas condiciones sus equipos mecánicos y componentes estructurales durante todo el tiempo de vida proyectada. En ese sentido, las placas antidesgaste son planchas de alta dureza que recubren las paredes internas de equipos mineros, tales como tolvas, chutes, molinos, entre otros. Sin embargo, a pesar de su alta dureza, las placas antidesgaste pierden material por causa de la abrasión provocada por el deslizamiento del material granulado de las operaciones mineras. Asimismo, las placas antidesgaste son reemplazadas cuando su espesor alcanza un desgaste de $60 \%$, debido a limitaciones del sistema actual sujeción. Por ende, existe la necesidad de evaluar nuevas alternativas de diseño que permitan ampliar el porcentaje de desgaste y así extender la vida útil de las placas antidesgaste.

El diseño actual del sistema de sujeción, conformado por una unión atornillada y una particular forma constructiva de la placa antidesgaste, se aprecia en la Figura 1a. Este diseño presenta el inconveniente de que la cabeza del tornillo se desgasta junto con la placa antidesgaste, producto de la abrasión del material granulado. Cuando la placa antidesgaste se desgasta lo suficiente (aproximadamente un $60 \%$ ), la cabeza del tornillo también se ha desgastado, al punto de no cumplir con su función. Por este motivo es necesario reemplazar la placa antidesgaste, a pesar de poseer suficiente espesor remanente para continuar en operación. Un nuevo diseño del sistema de sujeción, que permita extender la vida útil de la placa, tendría gran impacto en los costos de mantenimiento de la empresa minera. Las actuales placas se encuentran recubriendo las paredes internas de un chute de transferencia en forma de pirámide invertida trunca, como se aprecia en la Figura 1b. En la práctica, se observa que las placas más solicitadas son aquellas que se encuentra en las filas inferiores de las paredes, debido a que éstas reciben la mayor presión ejercida por la pila de material granulado acumulado. La placa antidesgaste más solicitada es objeto de estudio.

En la literatura es posible encontrar trabajos de diversos autores que proponen mejoras a los diseños de las placas antidesgaste. Por ejemplo, Davies (2011) implementa mejoras a un diseño de placa antidesgaste debido a la presencia de dificultades asociadas a los procesos de fabricación del sistema de sujeción, el cual emplea tornillos de cabeza avellanada. Davies propone el empleo de tornillos de cabeza troncocónica y agujeros en las placas antidesgaste, cuya forma permite que la cabeza de los tornillos encaje sin problemas. Igualmente, Elston (2015) propone una similar alternativa a la brindada por Davies. Elston presenta un sistema de sujeción que emplea el mismo principio, pero a diferencia de Davies, el tornillo se fabrica a partir de un espárrago con una cabeza fundida del mismo material de la placa antidesgaste. Cabe señalar que ambos trabajos revelan la búsqueda de mejoras del desempeño de las placas antidesgaste, para lo cual proponen alternativas de diseño del sistema de sujeción.

Por otro lado, diferentes autores realizan estudios experimentales para evaluar el desempeño de placas antidesgaste bajo condiciones reales de operación. En ese sentido, Valtonen (2019) realiza ensayos para determinar el desempeño de un tipo específico de placa fabricado con diferentes aceros resistentes al desgaste. En otro estudio, Ali (2019) evalúa experimentalmente el desempeño de una placa antidesgaste de hierro fundido blanco dentro de un molino de bolas. Si bien es cierto, se encuentran trabajos en la literatura que emplean ensayos experimentales, éstos demandan una fuerte inversión de tiempo y de recursos económicos. Además, los trabajos reportados están orientados principalmente a estudiar el fenómeno del desgaste y no el diseño del sistema de sujeción. La mayoría de los diseños de placas antidesgaste emplean uniones atornilladas como sistema de sujeción, razón por la cual es importante estudiar su comportamiento. Una forma de evaluar el comportamiento de las uniones atornilladas es mediante la simulación numérica por el Método de los Elementos Finitos (FEM, por sus siglas en inglés). En ese sentido, autores plantean diversas técnicas para desarrollar modelos numéricos adecuados.

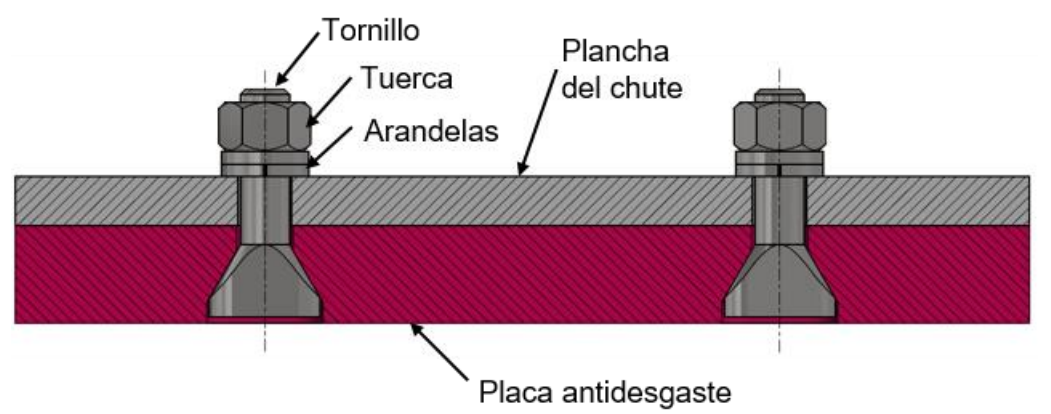

a)

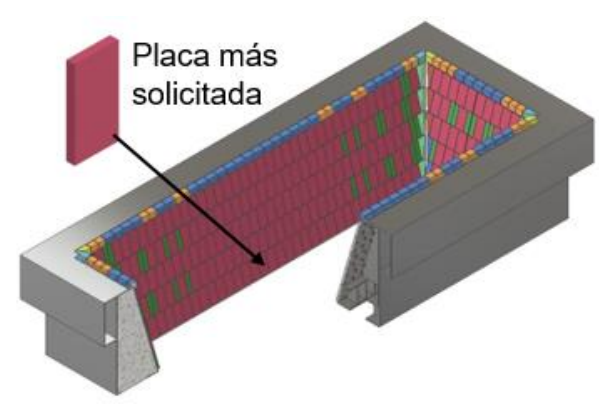

b)

Fig. 1: a) Vista de sección del diseño actual del sistema de sujeción de la placa antidesgaste, b) chute de transferencia recubierto por placas antidesgaste. 
Así, por ejemplo, Yu (2015) desarrolla modelos numéricos de forma minuciosa de las uniones atornilladas, puesto que su trabajo consiste en encontrar el parámetro con mayor influencia en la relación de torque de apriete y fuerza de pretensión, que resultó ser el coeficiente de fricción entre los hilos de la unión roscada. Sin embargo, en un trabajo interesante planteado por Wu (2012) no es necesario modelar los hilos de la rosca de la unión atornillada. Wu desarrolla un estudio comparativo de diferentes modelos numéricos de uniones atornilladas que son empleadas en conexiones semirrígidas viga-columna. En su estudio, Wu propone un modelo numérico de unión atornillada donde la parte roscada del vástago del tornillo es reemplazada por un cilindro equivalente con el diámetro resistente del tornillo. Asimismo, Wu logra simplificar el modelo adicionando el espesor de la arandela a la tuerca, y juntando todo el conjunto como una única pieza. De esta manera, el autor logra desarrollar un modelo de tornillo conveniente y eficiente, en términos de precisión y de recursos computacionales.

Otros estudios que emplean simulación numérica, para el análisis del comportamiento mecánico de componentes estructurales, reportan la importancia de utilizar modelos constitutivos y criterios de falla adecuados. Para materiales frágiles, por ejemplo, Park (2017) utiliza el modelo de material Cast Iron para estudiar el comportamiento estructural de un tipo de concreto, obteniendo resultados adecuados y en concordancia con valores experimentales. El modelo Cast Iron es originalmente un modelo de plasticidad para modelar un hierro fundido gris, sin embargo, su uso se extiende para modelar materiales que poseen un comportamiento mecánico distinto en tracción que en compresión. Por otro lado, para modelar materiales dúctiles, Hwang (2013) emplea el modelo elasto-plástico bilineal para mode los materiales de una unión atornillada. En su trabajo, Hwang simula el proceso de instalación de tornillos en un mecanismo automotriz determinando numéricamente el valor de torque necesario para asegurar la sujeción, resultando en un modelo adecuado que capta de manera precisa el comportamiento mecánico real. Asimismo, la literatura muestra que un criterio de falla adecuado para evaluar a los materiales frágiles es el criterio de Mohr-Coulomb, mientras que, para los materiales dúctiles, el criterio de falla más utilizado es el de Von Mises.

El presente trabajo realiza un estudio comparativo entre dos alternativas de diseño del sistema de sujeción de placas antidesgaste utilizadas en chutes mineros. Para ello, evalúa el comportamiento mecánico del sistema de sujeción de ambas alternativas mediante simulación numérica basada en FEM. El estudio desarrolla modelos numéricos de los componentes principales que son: la placa antidesgaste, una plancha de acero que representa una porción de la estructura del chute y el sistema de sujeción. Asimismo, el estudio determina el estado de esfuerzos de cada componente considerando la variación del espesor de la placa antidesgaste que representa los diferentes niveles de desgaste de la misma. Adicionalmente, el estudio emplea modelos constitutivos de comportamiento frágil para la placa antidesgaste y de comportamiento dúctil para la plancha del chute y el sistema de sujeción. Cabe indicar también que se realizan ensayos experimentales en una máquina de tracción para validar los modelos numéricos del sistema de sujeción. Los modelos numéricos validados son empleados posteriormente para analizar las alternativas propuestas bajo condiciones reales de operación.

\section{ALTERNATIVAS DE DISEÑO}

El diseño actual del sistema de sujeción está conformado por una unión atornillada (un tornillo cabeza T, dos arandelas y una tuerca) y un agujero en la placa antidesgaste, cuya forma permite que la cabeza $T$ de los tornillos pueda encajar, tal como se aprecia en la Figura 2a. Durante el montaje, la unión atornillada genera la fuerza de pretensión, la cual hace que la cabeza del tornillo ejerza presión sobre las superficies de contacto, quedando comprimida la placa antidesgaste contra la plancha estructural del chute. La alternativa 1 propone un sistema de sujeción conformado por una unión atornillada (un tornillo cabeza hexagonal, dos arandelas y una tuerca), una protuberancia de forma cilíndrica en la placa antidesgaste y una tapa de ajuste. La protuberancia contiene una cavidad interna hexagonal para alojar la cabeza del tornillo. La alternativa 1 se muestra en la Figura $2 b$. Por su parte, el diseño propuesto en la alternativa 2, consiste en una unión atornillada (un espárrago, dos arandelas y una tuerca). El espárrago se inserta durante el proceso de fabricación (fundición) de la placa antidesgaste, de tal forma que el material fundido de la placa se adhiere a la rosca del espárrago, como se puede apreciar en la Figura 2c.

Respecto a las características de cada alternativa, se puede comentar que la alternativa 1 aleja por completo el sistema de sujeción del contacto con el material granulado. Este nuevo diseño requiere de una inversión adicional de material y de los procesos de fabricación asociados, ya que la placa antidesgaste cuenta con una protuberancia cilíndrica, provista de una cavidad que aloja la cabeza de un tornillo hexagonal. Además, cuenta con una tapa de ajuste, gracias a la cual los elementos de unión pueden fijar la placa a la plancha del chute. Por otro lado, la alternativa 2 se caracteriza por su sencillez constructiva. Esta alternativa cuenta con un espárrago que es insertado durante el proceso de fundición de la placa antidesgaste. Similar al diseño original, el espárrago atraviesa la placa antidesgaste y se desgasta junto con esta. La diferencia es que el espárrago se mantiene siempre unido a la placa, mientras que en el diseño original la placa queda totalmente liberada 
cuando se desgasta la cabeza del tornillo. El desempeño de esta alternativa depende de la correcta alineación del espárrago respecto a la placa, pero principalmente de la calidad de la adherencia que se logre entre el espárrago y la placa durante el proceso de fundición.

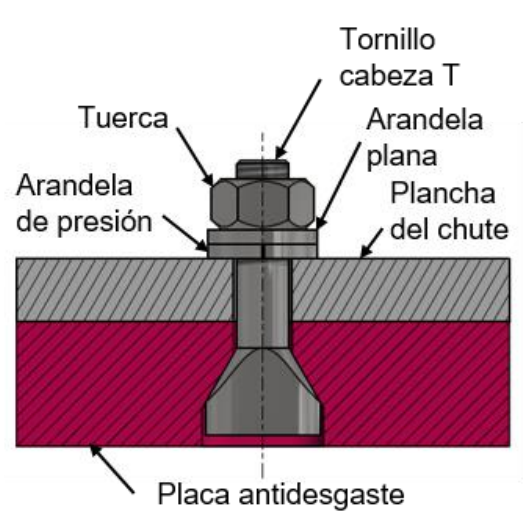

a)

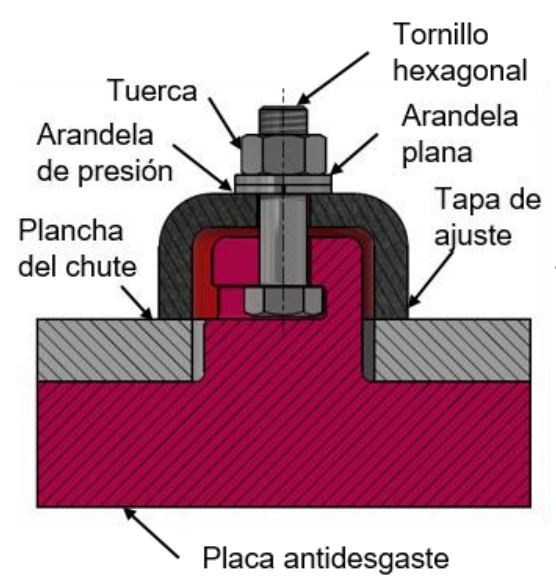

b)

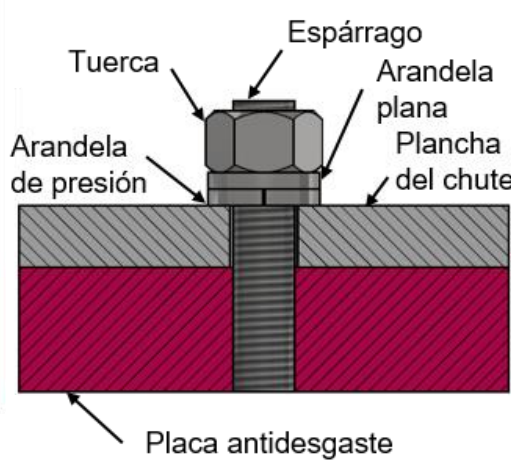

c)

Fig. 2: Vistas de sección del sistema de sujeción, a) diseño actual, b) alternativa 1, c) alternativa 2

\section{METODOLOGÍA}

Dada la complejidad de efectuar el análisis comparativo mediante ensayos físicos en condiciones reales de operación, el presente trabajo emplea la simulación numérica basada en FEM. En primer lugar, se lleva a cabo un estudio experimental que comprende desde la fabricación de probetas no convencionales hasta ensayos en laboratorio. Las probetas representan el sistema de sujeción real, sin incluir la tuerca, que es sustituida por un accesorio de la máquina de ensayos. Los ensayos experimentales consisten en aplicar lentamente una carga de tracción en el tornillo hasta alcanzar la falla mecánica y, por ende, determinar la carga máxima que soportan las probetas y su modo de falla.

En segundo lugar, se procede con el estudio de simulación que consiste en la implementación de modelos numéricos para el análisis del sistema de sujeción. La simulación busca reproducir los ensayos experimentales descritos en el párrafo anterior, donde se toman en cuenta las características geométricas de las probetas fabricadas, así como las restricciones y la carga aplicada durante los ensayos. La comparación entre los resultados experimentales y numéricos permite la validación de los modelos constitutivos de material y de los criterios de falla implementados. Finalmente, los modelos numéricos validados son empleados para el estudio comparativo de las alternativas bajo condiciones reales de operación. Los modelos geométricos representan a los ensambles completos de los sistemas de sujeción. De igual manera, los modelos numéricos simulan las cargas reales de operación: fuerza de pretensión de la unión atornillada y cargas ejercidas sobre la placa por el material granulado.

\section{Ensayos experimentales}

Los ensayos experimentales determinan la carga máxima y el modo de falla de las probetas no convencionales de las dos alternativas propuestas. Los ensayos consisten en aplicar una carga uniaxial a las probetas mediante la máquina de tracción Mohr Federhaff Losenhausen, modelo MFL de 60 toneladas de capacidad. La carga es aplicada sobre el tornillo de forma gradual y a muy baja velocidad (cuasi estático) hasta alcanzar la falla mecánica del sistema de sujeción. Asimismo, las probetas están constituidas por tres componentes: la placa antidesgaste, la plancha de la estructura del chute y el componente roscado de sujeción (tornillo o espárrago, según la alternativa). La denominación no convencional se debe a que la configuración geométrica de la probeta no está estandarizada y, más bien, responde a una disposición real de operación de los componentes. Por último, durante los ensayos experimentales, se registra la carga aplicada hasta determinar la carga máxima y mediante inspección visual se evalúa el modo de falla de la probeta. A continuación, se describe la distribución y características de las probetas, así como la configuración y el procedimiento de los ensayos. Finalmente, se detallan los resultados experimentales obtenidos.

\section{Distribución de probetas según diseño}

La Tabla 1 muestra la distribución y las características generales de las probetas de las alternativas 1 y 2 . Se ensayan 3 probetas por cada una de las alternativas. El componente roscado de sujeción de la alternativa 1 es un tornillo de cabeza hexagonal M14, mientras que para la alternativa 2 es un espárrago de 3/4 de pulgada. 
Asimismo, el espesor de la plancha del chute para ambas alternativas es igual a $19 \mathrm{~mm}$, el espesor de la placa antidesgaste es de $7.5 \mathrm{~mm}$, lo que representa un espesor remanente equivalente a un $80 \%$ de desgaste. Por otro lado, la Figura 3 muestra las imágenes fotográficas de las probetas no convencionales, donde se aprecia la disposición de los componentes para los ensayos experimentales.

Tabla 1: Distribución y características generales de probetas no convencionales

\begin{tabular}{|l|l|l|l|l|l|l|}
\hline Diseño & $\begin{array}{l}\text { Cantidad de } \\
\text { probetas }\end{array}$ & $\begin{array}{l}\text { Componente de } \\
\text { sujeción }\end{array}$ & $\begin{array}{l}\text { Espesor de la } \\
\text { plancha del chute }\end{array}$ & $\begin{array}{l}\text { Espesor remanente } \\
\text { de la placa }\end{array}$ & $\begin{array}{l}\text { Porcentaje } \\
\text { de desgaste }\end{array}$ \\
\hline & & Tipo & Medida & $(\mathrm{mm})$ & $(\mathrm{mm})$ & $(\%)$ \\
\hline Alternativa 1 & 3 & T. Hexagonal & M14 & 19.0 & 7.5 & 80 \\
\hline Alternativa 2 & 3 & Espárrago & $3 / 4 "$ & 19.0 & 7.5 & 80 \\
\hline
\end{tabular}

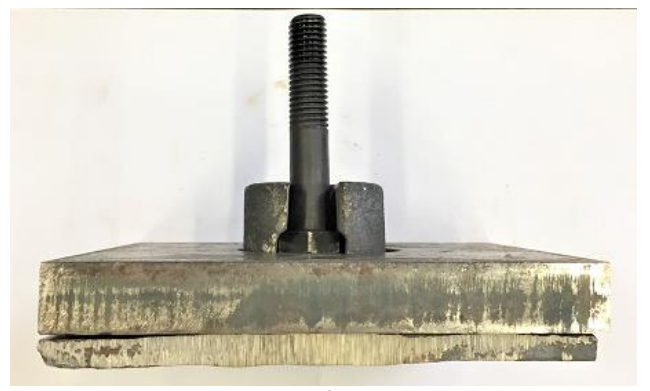

a)

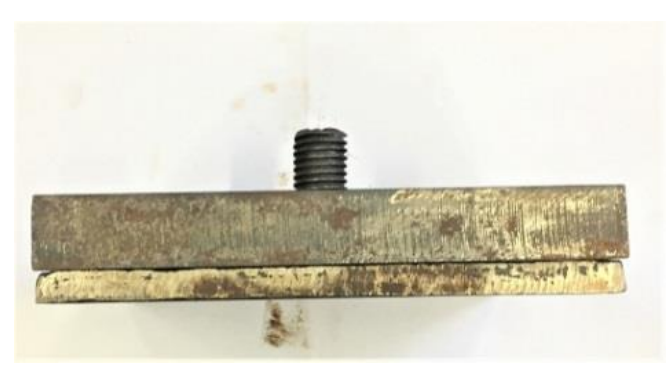

b)

Fig. 3: Probetas no convencionales, a) alternativa 1, b) alternativa 2

\section{Configuración y procedimiento de los ensayos experimentales}

La Figura 4a es una fotografía tomada durante un ensayo experimental, mientras que la Figura 4b muestra el esquema de la configuración de los mismos ensayos. Las mordazas de la máquina de tracción inmovilizan a la plancha del chute, mientras que un dispositivo de sujeción con elemento roscado sujeta el extremo libre del tornillo o espárrago, según la alternativa. El dispositivo de sujeción, que se encuentra conectado a la máquina, se desplaza lentamente en dirección vertical ascendente, lo cual provoca que tire del extremo libre del tornillo o espárrago. El tornillo o espárrago experimenta la carga de tracción y simultáneamente se genera una distribución de esfuerzos sobre los demás componentes. El ensayo concluye cuando alguno de los componentes de la probeta falla estructuralmente.

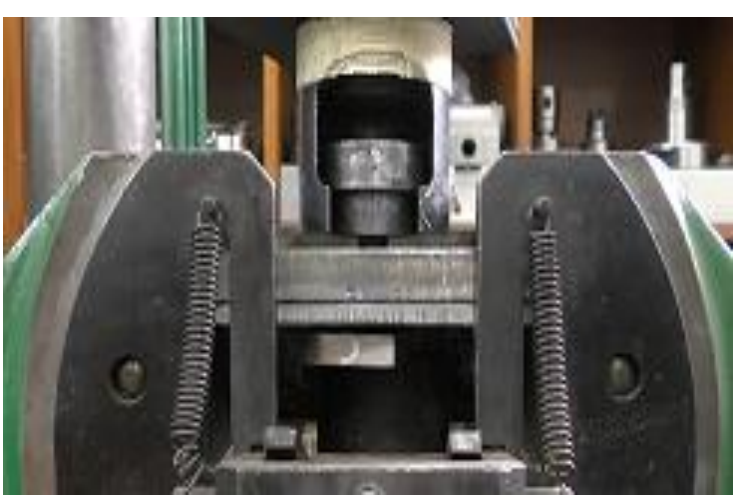

a)

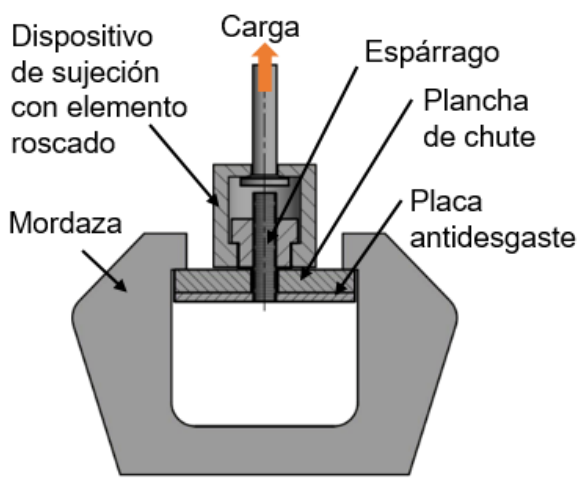

b)

Fig. 4: Ensayo experimental, a) imagen fotográfica, b) esquema de la configuración

\section{Resultados de los ensayos experimentales}

La Tabla 2 presenta los resultados experimentales obtenidos e información adicional acerca de la fuerza de pretensión según norma. Los resultados experimentales son: 1) la carga máxima registrada y 2) el modo de falla de la probeta ensayada. La alternativa 1 soporta una carga máxima promedio de $77 \mathrm{kN}$, mientras que la alternativa 2 soporta $111 \mathrm{kN}$. Respecto a la información adicional, de acuerdo con la norma ASTM A325, a cada unión atornillada le corresponde una fuerza de pretensión. Las fuerzas que corresponden a las alternativas 1 y 2 son de $61.4 \mathrm{kN}$ y $112.4 \mathrm{kN}$, respectivamente. Asimismo, un parámetro empleado en el análisis de los resultados es la relación de carga, la cual resulta de dividir la carga máxima registrada experimental entre la fuerza de pretensión según norma. El valor de relación de carga promedio para las alternativas 1 y 2 es de 1.3 y 1.0 , respectivamente. 
La Figura 5 muestra imágenes de los modos de falla de las probetas después ser ensayadas. El modo de falla común de la alternativa 1 es la fractura de la placa antidesgaste, observándose el desprendimiento de la protuberancia cilíndrica, tal como lo muestra la Figura 5a. En cambio, el modo de falla de la alternativa 2 es el desprendimiento del espárrago respecto a la placa antidesgaste, tal como se aprecia en la Figura 5b. Esto puede deberse, en parte, a la pérdida de adherencia entre el espárrago y la placa, así como a la fractura de los hilos de rosca de la placa.

Tabla 2: Resultados experimentales y fuerza de pretensión

\begin{tabular}{|c|c|c|c|c|c|c|c|}
\hline \multirow[b]{2}{*}{ Diseño } & \multicolumn{3}{|l|}{ Probeta } & \multicolumn{2}{|c|}{ Resultados experimentales } & \multicolumn{2}{|c|}{$\begin{array}{l}\text { Fuerza de pretensión } \\
\text { (ASTM A325) }\end{array}$} \\
\hline & $\begin{array}{l}\text { Elemento } \\
\text { roscado }\end{array}$ & $\begin{array}{l}\text { Espesor } \\
\text { remanente } \\
\text { placa }(\mathrm{mm})\end{array}$ & Probeta & $\begin{array}{l}\text { Carga } \\
\text { máxima } \\
(\mathrm{kN})\end{array}$ & Modo de falla & $\begin{array}{l}\text { Fuerza de } \\
\text { pretensión } \\
(\mathrm{kN})\end{array}$ & $\begin{array}{l}\text { Relación de } \\
\text { carga }\end{array}$ \\
\hline \multirow[t]{3}{*}{ Alternativa 1} & \multirow[t]{3}{*}{ M14 } & \multirow[t]{3}{*}{7.5} & P1 & 77.5 & $\begin{array}{l}\text { Fractura de la placa } \\
\text { y desprendimiento } \\
\text { de la protuberancia } \\
\text { cilíndrica }\end{array}$ & 61.4 & 1.26 \\
\hline & & & $\mathrm{P} 2$ & 73.0 & $\begin{array}{l}\text { Fractura de la placa } \\
\text { y desprendimiento } \\
\text { de la protuberancia } \\
\text { cilíndrica }\end{array}$ & 61.4 & 1.19 \\
\hline & & & P3 & 81.5 & $\begin{array}{l}\text { Fractura de una } \\
\text { parte de la } \\
\text { protuberancia } \\
\text { cilíndrica }\end{array}$ & 61.4 & 1.33 \\
\hline \multirow[t]{3}{*}{ Alternativa 2} & \multirow[t]{3}{*}{$3 / 4$ in } & \multirow[t]{3}{*}{7.5} & P1 & 113.5 & $\begin{array}{l}\text { Desprendimiento } \\
\text { entre el espárrago y } \\
\text { la placa }\end{array}$ & 112.4 & 1.01 \\
\hline & & & P2 & 107.0 & $\begin{array}{l}\text { Desprendimiento } \\
\text { entre el espárrago y } \\
\text { la placa }\end{array}$ & 112.4 & 0.95 \\
\hline & & & P3 & 114.0 & $\begin{array}{l}\text { Desprendimiento } \\
\text { entre el espárrago y } \\
\text { la placa }\end{array}$ & 112.4 & 1.01 \\
\hline
\end{tabular}

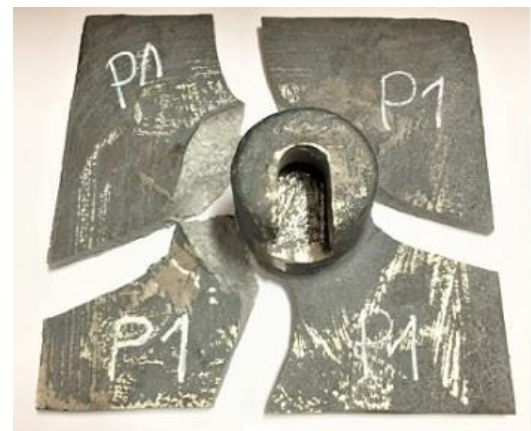

a)
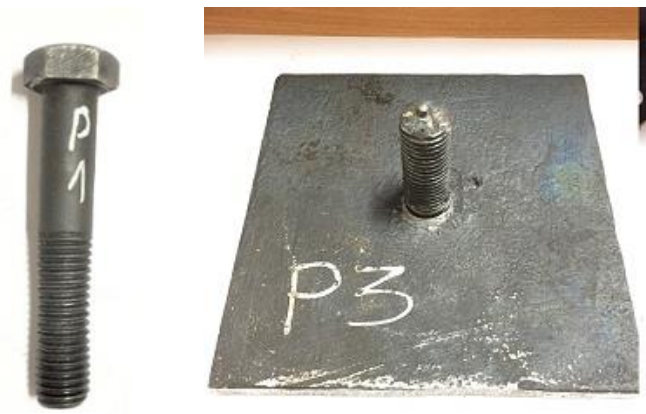

b)

Fig. 5: Modo de falla de las probetas no convencionales, a) alternativa 1, b) alternativa 2

\section{Modelado numérico}

En las siguientes secciones se describe el modelado numérico que se usa para evaluar las alternativas de diseño del sistema de sujeción descritas anteriormente. Inicialmente, el modelo numérico se aplica al análisis de los mismos casos ensayados experimentalmente, con el objetivo de validarlo. Para esto, se desarrollan los modelos geométricos tridimensionales de las probetas empleadas en el estudio experimental, que luego son discretizados. Se seleccionan los modelos constitutivos y se definen los criterios de falla para los diferentes materiales. Además, se establecen las condiciones de contorno que representan, de la forma más fiel posible, las condiciones de los ensayos experimentales. El estudio realizado corresponde a un análisis estático no lineal que, a través de un proceso iterativo, permite validar el modelo. El modelo numérico se implementa en la plataforma del software comercial ANSYS Mechanical 19.0 (ANSYS, 2018). Para una mejor comprensión del modelado numérico realizado, este se divide en las tres etapas típicas de un análisis por simulación numérica: pre procesamiento, solución y post procesamiento. 


\section{Etapa de pre procesamiento}

En la etapa de pre procesamiento se configuran los modelos numéricos de las alternativas de diseño de los sistemas de sujeción, a través de las siguientes etapas: 1) definición del modelo geométrico tridimensional, 2) mallado, 3) definición de los modelos de material y 4) configuración de las condiciones de borde y contactos.

\section{Definición del modelo geométrico tridimensional}

El modelado geométrico de los componentes es generado a partir de las dimensiones características de las probetas ensayadas experimentalmente, las cuales se indican en la Figura 6. Siguiendo las recomendaciones de Wu (2012) y de acuerdo a la norma ASTM A325-10, el extremo roscado del tornillo M14 se modela como un cilindro liso con un diámetro resistente de $11.9 \mathrm{~mm}$ y el cuerpo del espárrago de 3/4 de pulgada con un diámetro de $16.6 \mathrm{~mm}$. Gracias a la simetría de los modelos geométricos, se desarrolla solamente la mitad de los mismos. En el caso particular de la alternativa 2, el espárrago y la placa son modelados como una única pieza (cada uno con su material), considerando que se alcanza una completa adherencia entre el material de la placa y los hilos de rosca del espárrago durante el proceso de fundición.

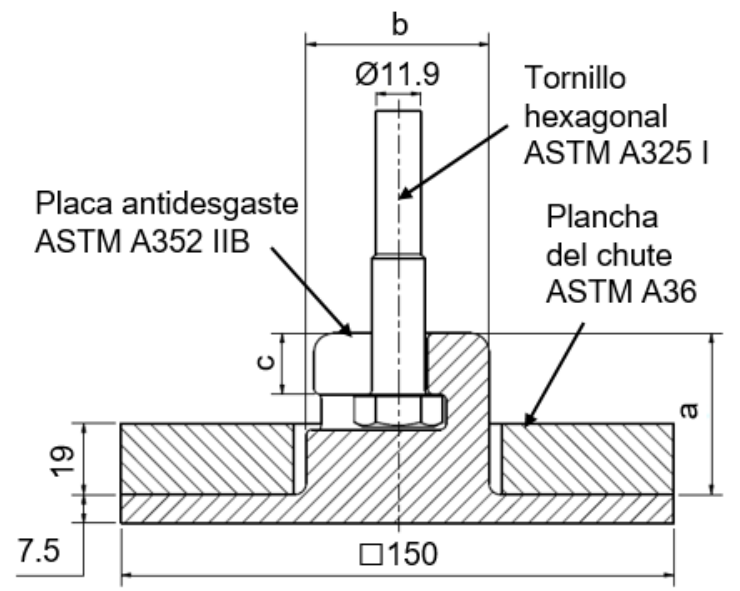

a)

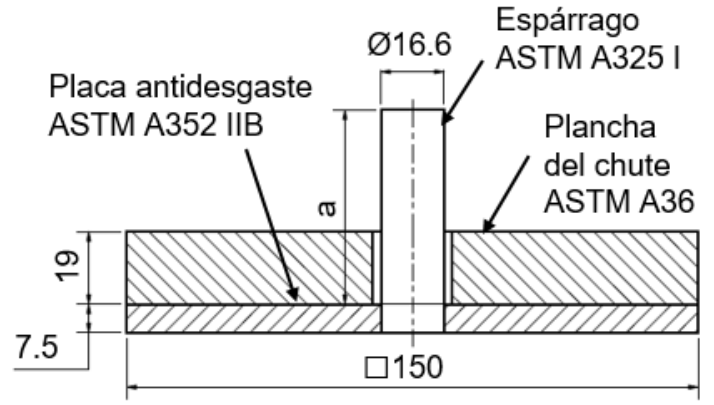

b)

Fig. 6: Características geométricas, a) alternativa 1, b) alternativa 2

Mallado

Los modelos son discretizados utilizando elementos tetraédricos de segundo orden. Además, la estrategia de mallado consiste en refinar las zonas de interés también llamadas zonas críticas, que son aquellas donde los esfuerzos resultantes son más altos para cada alternativa de diseño. Así, para la alternativa 1, la zona crítica está ubicada en la base de la protuberancia cilíndrica, mientras que para la alternativa 2, la zona crítica está ubicada en la superficie de adherencia entre la placa y el espárrago. Luego, se realiza un estudio de independencia de malla para obtener tamaños de elementos adecuados, a partir de la convergencia de los resultados numéricos. De esta manera, para la alternativa 1 se obtuvo un tamaño de elemento en la zona crítica de $1.5 \mathrm{~mm}$ y $3.0 \mathrm{~mm}$ en zonas alejadas, mientras que para la alternativa 2, se obtuvo un tamaño de elemento en la zona crítica de $0.5 \mathrm{~mm}$ y $3.0 \mathrm{~mm}$ en zonas alejadas. El modelo final de la alternativa 1 posee 96417 elementos y 140516 nodos (Figura 7a), mientras que el modelo de la alternativa 2 posee 103212 elementos y 150642 nodos (Figura $7 b$ ).

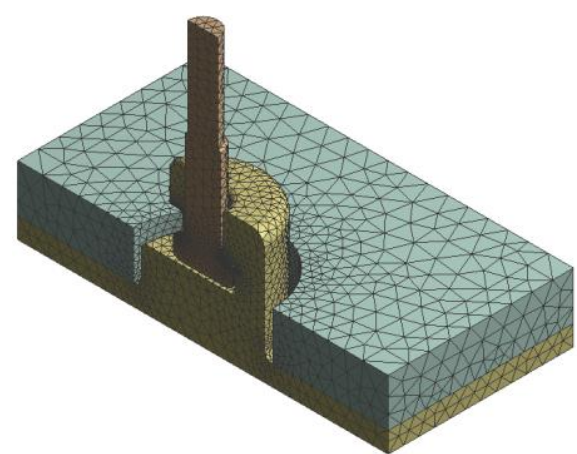

a)

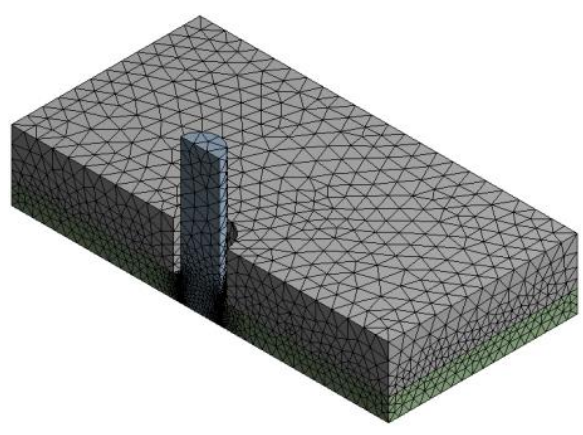

b)

Fig. 7: Mallado, a) alternativa 1, b) alternativa 2 


\section{Definición de modelos constitutivos}

El material de las placas antidesgaste es hierro fundido blanco ASTM A532 Clase II Tipo B y presenta un comportamiento frágil. Por otro lado, el material de los componentes de la unión atornillada es ASTM A325 Tipo I y el material de la plancha estructural del chute es ASTM A36, ambos materiales se comportan de forma dúctil. La Tabla 3 muestra las propiedades mecánicas de las tres componentes presentes en el modelo numérico, necesarias para definir los modelos constitutivos correspondientes.

Tabla 3: Propiedades mecánicas de los materiales

\begin{tabular}{|c|c|c|c|c|c|c|c|c|}
\hline \multirow[t]{3}{*}{ Componente } & \multirow[t]{3}{*}{ Material } & \multirow{2}{*}{$\begin{array}{l}\text { Densidad } \\
\left(\mathrm{kg} / \mathrm{m}^{3}\right)\end{array}$} & \multirow{2}{*}{$\begin{array}{l}\text { Módulo de } \\
\text { Elasticidad } \\
\text { (MPa) }\end{array}$} & \multirow{2}{*}{$\begin{array}{l}\text { Coef. de } \\
\text { Poisson }\end{array}$} & \multirow{2}{*}{$\begin{array}{l}\text { Esf. de } \\
\text { Fluencia } \\
\text { (MPa) }\end{array}$} & \multicolumn{2}{|c|}{ Esf. Último (MPa) } & \multirow{2}{*}{$\begin{array}{l}\text { Deformación } \\
\text { ingenieril } \\
(\mathrm{mm} / \mathrm{mm})\end{array}$} \\
\hline & & & & & & Tensión & Compresión & \\
\hline & & $\rho$ & $\mathrm{E}$ & $\mathrm{v}$ & $\sigma_{y}$ & \multicolumn{2}{|l|}{$\sigma_{u}$} & $\varepsilon$ \\
\hline $\begin{array}{l}\text { Placa } \\
\text { antidesgaste }\end{array}$ & $\begin{array}{l}\text { ASTM } \\
\text { A532 II B }\end{array}$ & 7600 & $2.00\left(10^{5}\right)$ & 0.28 & - & 485 & 970 & - \\
\hline $\begin{array}{l}\text { Componente } \\
\text { de sujeción }\end{array}$ & $\begin{array}{l}\text { ASTM } \\
\text { A325 I }\end{array}$ & 7850 & $2.00\left(10^{5}\right)$ & 0.30 & 634 & 827 & & 0.14 \\
\hline $\begin{array}{l}\text { Plancha del } \\
\text { chute }\end{array}$ & $\begin{array}{l}\text { ASTM } \\
\text { A36 }\end{array}$ & 7850 & $2.00\left(10^{5}\right)$ & 0.30 & 250 & 460 & & 0.21 \\
\hline
\end{tabular}

Acerca de los modelos constitutivos, se define un modelo Cast Iron (ANSYS, 2018) para el material frágil de la placa antidesgaste. Este modelo permite definir distintos límites en tracción $\left(\sigma_{u T}\right)$ y compresión $\left(\sigma_{u c}\right)$. Se utiliza un comportamiento elasto-plástico perfecto, para describir tanto la tracción como la compresión. Este comportamiento elasto-plástico perfecto significa que, una vez que se haya alcanzado el esfuerzo límite, ya sea en tracción o en compresión, el material deja de ofrecer resistencia. En otras palabras, cuando se alcanza el esfuerzo límite se produce la falla o fractura del material. El modelo Cast Iron se aprecia en la Figura 8a. Por otro lado, se selecciona el modelo elasto-plástico bilineal para los materiales dúctiles de la unión atornillada y de la plancha de la estructura del chute. Este modelo elasto-plástico bilineal posee un primer tramo elástico, limitado por el esfuerzo de fluencia $\left(\sigma_{y}\right)$. Luego, el modelo representa la plasticidad del material con endurecimiento isotrópico mediante un segundo tramo, definido por el modulo tangente $\left(E_{t}\right)$ como se muestra en la Figura $8 \mathrm{~b}$. El valor de $\mathrm{E}_{\mathrm{t}}$ se estima en base a las deformaciones reales del material, tal como lo propone Mac (2011).

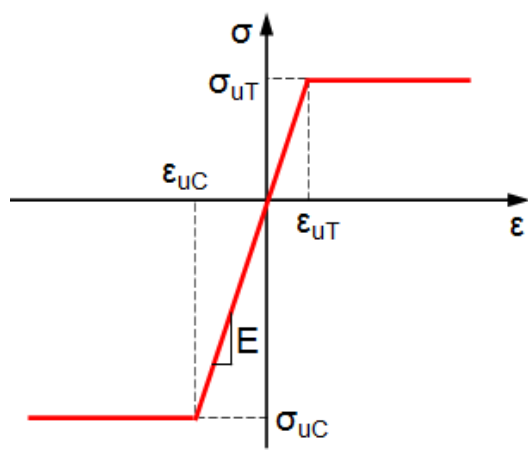

a)

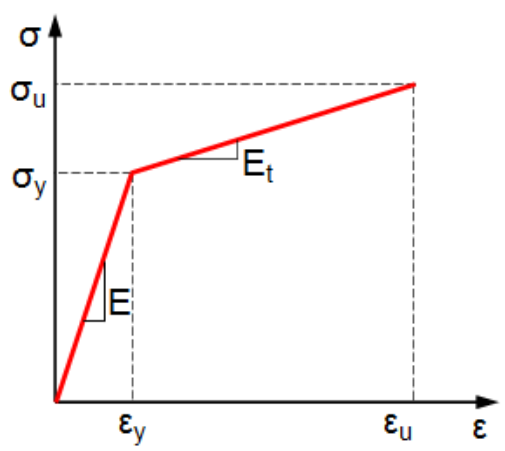

b)

Fig. 8: Modelos constitutivos, a) material frágil, b) material dúctil

\section{Configuración de condiciones de borde y contactos}

De acuerdo con los ensayos experimentales, las mordazas inmovilizan la plancha del chute, mientras que un dispositivo roscado sujeta el extremo libre del tornillo o espárrago, según la alternativa, y se desplaza lentamente en dirección vertical ascendente. En ese sentido, como se aprecia en la Figura 9, sobre los extremos de la plancha del chute de ambos modelos, se restringe el movimiento, lo cual representa la acción de las mordazas sobre las probetas. Asimismo, sobre la sección circular del extremo libre del tornillo o espárrago, se impone un desplazamiento vertical, en forma gradual, que produce como reacción la fuerza de tracción correspondiente. Esta fuerza de tracción es monitoreada hasta que alcanza su valor máximo y comienza a disminuir, en cuyo instante se detiene la simulación. Por último, se activa la aceleración de gravedad $\left(\mathrm{g}=9.81 \mathrm{~m} / \mathrm{s}^{2}\right)$ y se aplica la condición de simetría del modelo. Dependiendo de la alternativa que se analiza se definen las parejas de contacto, todas del tipo contacto con fricción. En ambas alternativas se define el contacto entre la placa antidesgaste y la plancha del chute. Adicionalmente, en la alternativa 1 se define el contacto entre la cabeza del tornillo y el asiento de la cavidad hexagonal de la protuberancia de la 
placa antidesgaste. En el caso de la alternativa 2, el espárrago y la placa antidesgaste están adheridos entre sí, conformando una sola pieza, por lo que no se define algún contacto. Es importante aclarar que entre el tornillo o espárrago y la plancha del chute existe una holgura y no entran en contacto en ningún momento. De acuerdo con la literatura, en las parejas de contacto con participación de la placa antidesgaste, se toma un coeficiente de fricción estática igual a 0.4 (Xu, 2010 y Vadiraj, 2012).

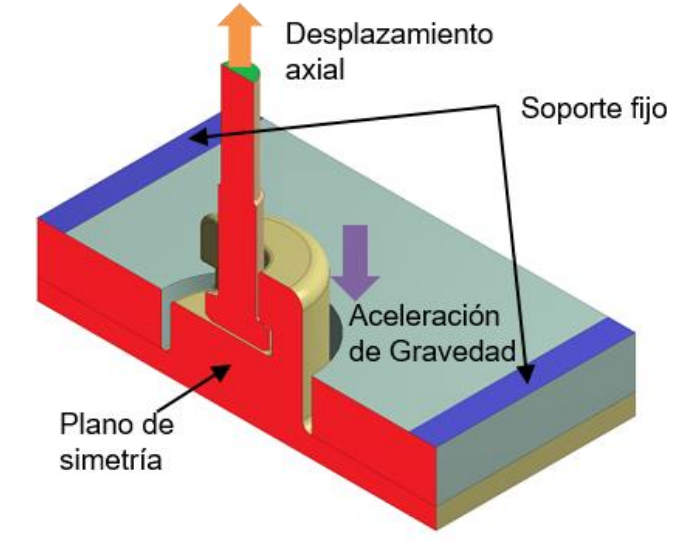

a)

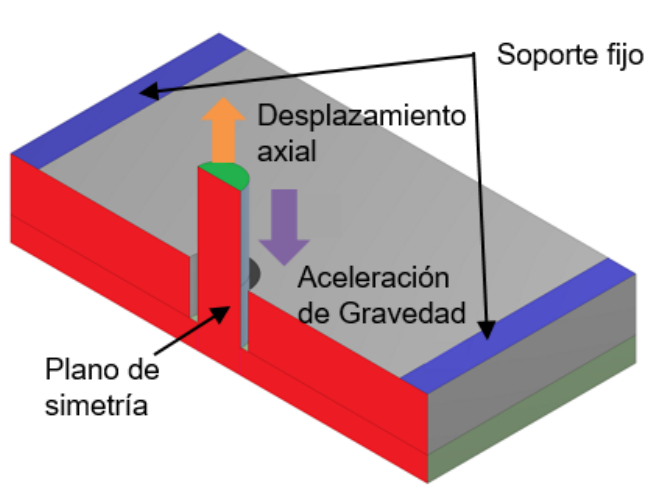

b)

Fig. 9: Condiciones de borde, a) alternativa 1, b) alternativa 2

\section{Etapa de solución}

Se impone un desplazamiento gradual en dirección vertical, el cual se va incrementando en cada iteración. La magnitud del incremento del desplazamiento se determina en función del incremento de la carga de tracción correspondiente. Durante las primeras iteraciones del análisis numérico, la carga de tracción crece con una tasa significativa y se establece un incremento de desplazamiento igual a $0.02 \mathrm{~mm}$. Luego, en las iteraciones intermedias, la tasa de crecimiento de la carga de tracción comienza a disminuir. Por esta razón, en este intervalo se establece un incremento de desplazamiento igual a $0.01 \mathrm{~mm}$, la mitad del anterior. Finalmente, en las últimas iteraciones, cuando la tasa de crecimiento de la carga de tracción es aún menor, se impone un incremento de desplazamiento igual a $0.005 \mathrm{~mm}$. Esta estrategia busca captar con la mayor precisión posible la carga máxima del sistema de sujeción, la cual será comparada con el valor obtenido experimentalmente.

\section{Etapa de post procesamiento}

Para evaluar el comportamiento mecánico de los sistemas de sujeción se emplea el factor de seguridad (FS). En el caso de la placa antidesgaste, la cual posee un comportamiento frágil, se emplea el esfuerzo último del material como esfuerzo límite y la teoría de Mohr Coulomb como criterio de falla. Mientras que, para la plancha del chute y los elementos de la unión atornillada, ambos de comportamiento dúctil, se emplea el esfuerzo de fluencia como esfuerzo límite y el criterio de falla de Von Mises. La Figura 10 y la Figura 11 muestran los resultados del análisis para la alternativa 1 y alternativa 2, respectivamente. En ambas alternativas, la falla ocurre por zonas de la placa antidesgaste, donde el material tiene un comportamiento frágil. Las regiones de color rojo indican un FS menor que 1, mientras que las de color azul indican un FS mayor que 10. La Figura 10 revela que la zona crítica de la alternativa 1 está ubicada en la superficie de redondeo donde se empalma la protuberancia cilíndrica con la placa. Asimismo, la Figura 11 muestra que la zona crítica de la alternativa 2 está ubicada en la superficie de adherencia entre la placa y el espárrago.

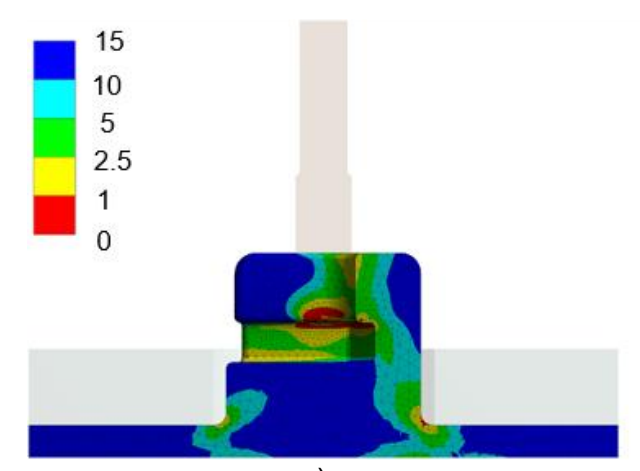

a)

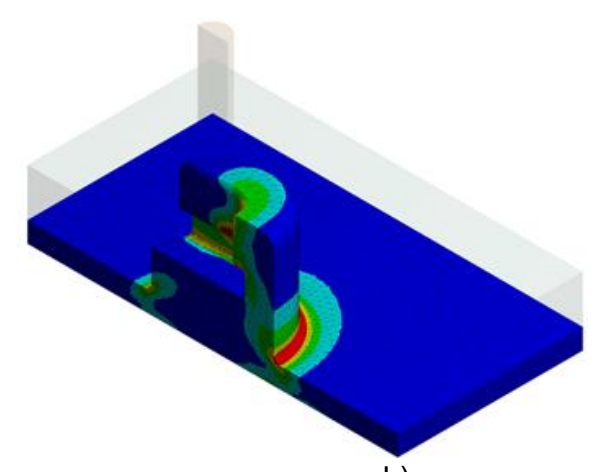

b)

Fig. 10: Distribución del factor de seguridad de la alternativa 1, a) vista lateral, b) vista isométrica 


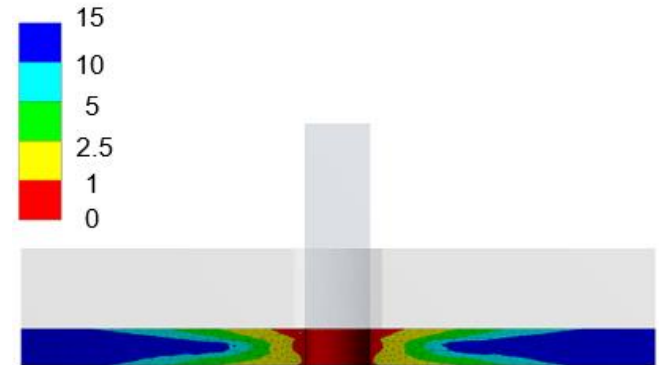

a)

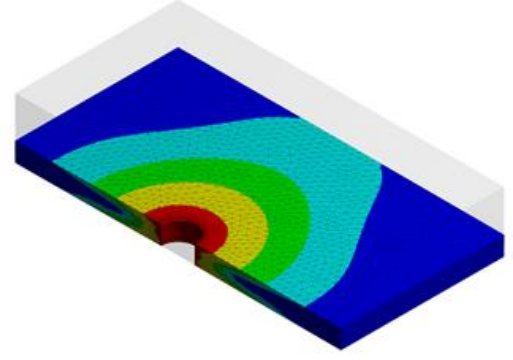

b)

Fig. 11: Distribución del factor de seguridad de la alternativa 2, a) vista lateral, b) vista isométrica

\section{Validación del modelo numérico}

Las gráficas de la Figura 12 muestran la evolución de la carga de tracción en función del desplazamiento, tanto para los resultados experimentales (líneas de trazos) como numéricos (líneas continuas). Por simple inspección, se observa que los resultados experimentales y numéricos poseen la misma tendencia, existiendo aparentemente una adecuada correspondencia entre los mismos. Sin embargo, para validar los modelos numéricos, se requiere profundizar cuantitativamente en el análisis de estos resultados, aspecto que se detalla a continuación.
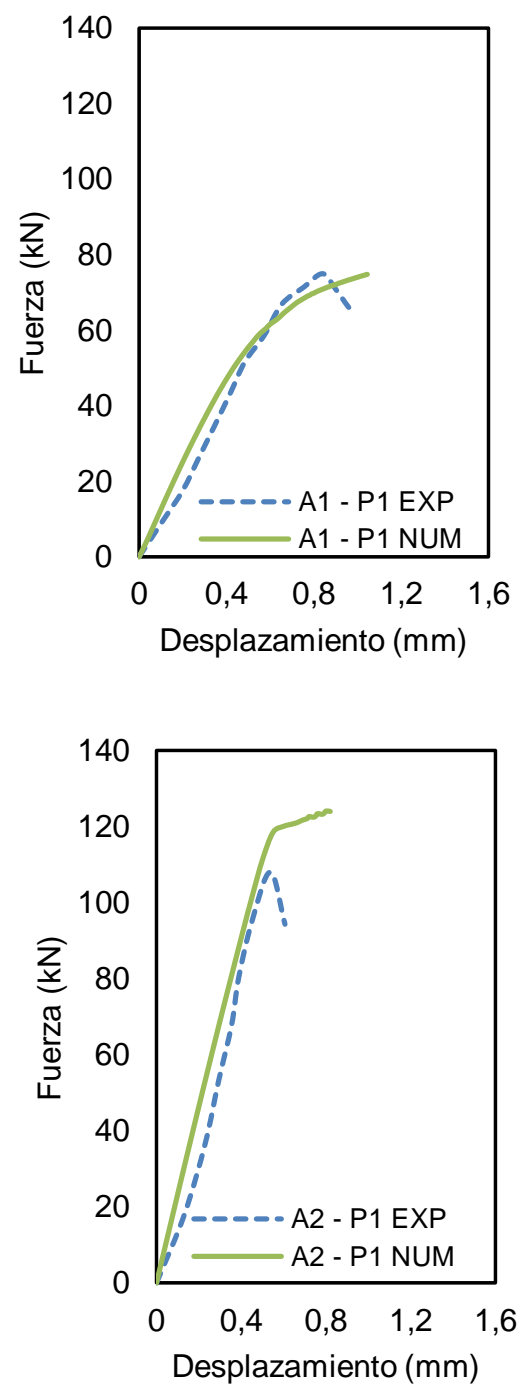

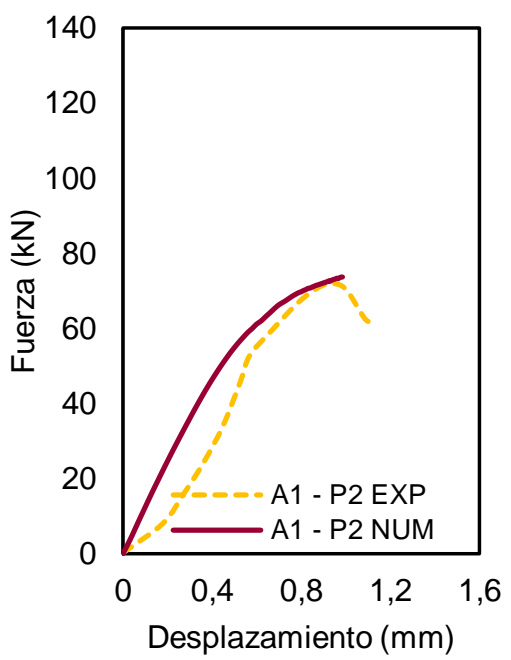

a)

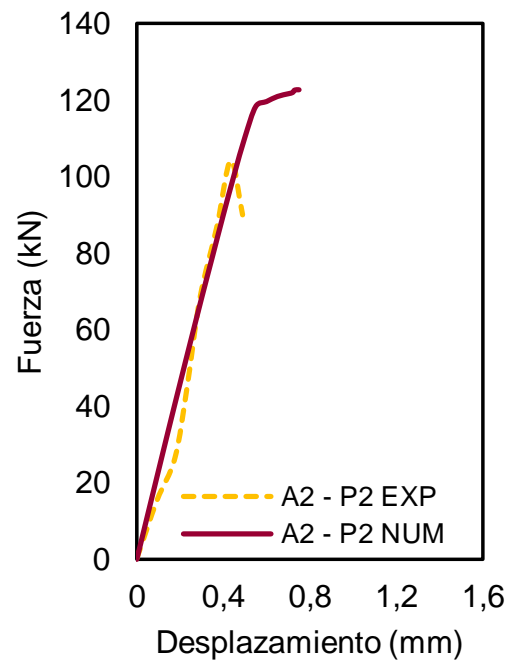

b)
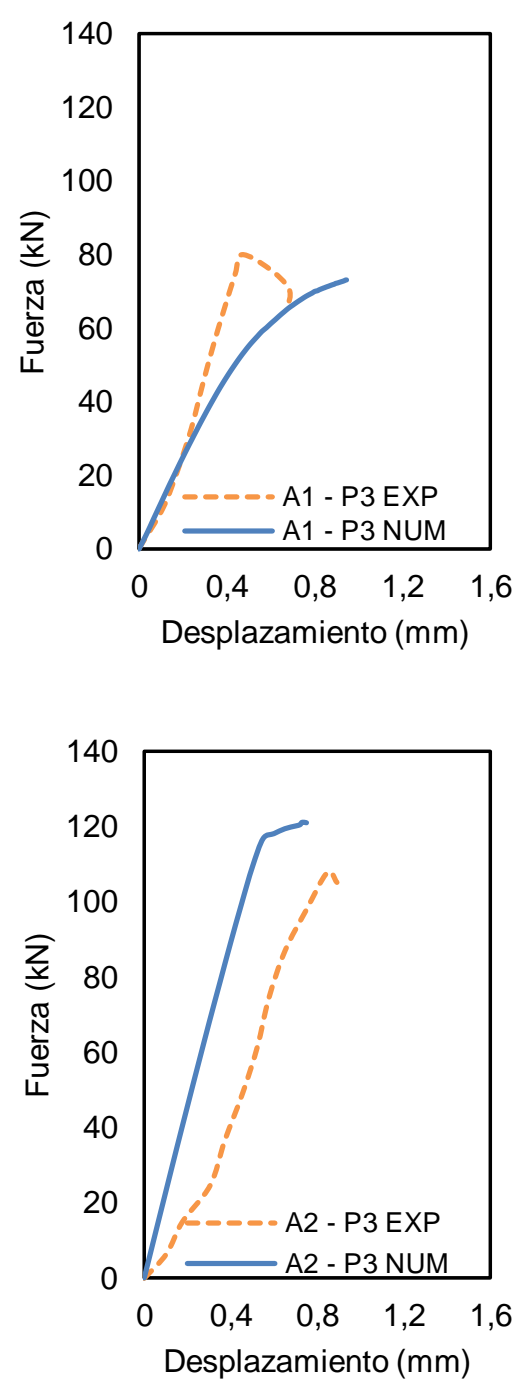

Fig. 12: Comparación de resultados experimentales (EXP) y numéricos (NUM), a) alternativa 1, b) alternativa 2 
Para cuantificar la diferencia entre los resultados experimentales y numéricos, se definen dos parámetros de comparación: 1) carga de tracción máxima y 2) pendiente de la curva. La carga de tracción máxima es la fuerza más alta registrada en la curva, que para el resultado numérico de la alternativa 2 se ha tomado como el punto de quiebre, claramente identificado en las curvas correspondientes. La pendiente de una curva se determina como la pendiente de la recta que une el origen de coordenadas con el punto de la curva correspondiente a la carga de tracción máxima.

La Tabla 4 detalla las diferencias relativas que resultan de la comparación entre los resultados experimentales y numéricos. Se observa que la diferencia relativa de la carga de tracción máxima es inferior al $10 \%$ en la gran mayoría de casos. Sólo en un caso de la alternativa 2 el valor máximo es ligeramente superior, alcanzando el $13.6 \%$. Asimismo, se observa que la diferencia relativa entre las pendientes experimentales y numéricas es aceptable, aunque alcanza valores superiores al $50 \%$ en dos de los seis casos. Finalmente, de acuerdo con los resultados obtenidos, se concluye que existe una adecuada correspondencia entre los valores experimentales y numéricos. Esto permite emplear los modelos desarrollados en el estudio de las alternativas de diseño de los sistemas de sujeción bajo condiciones reales de operación.

Tabla 4: Parámetros de comparación de las curvas fuerzas desplazamiento

\begin{tabular}{|c|c|c|c|c|c|c|c|}
\hline \multirow[b]{2}{*}{ Diseño } & \multirow[b]{2}{*}{ Probeta } & \multicolumn{3}{|c|}{ Carga máxima $(k N)$} & \multicolumn{3}{|c|}{ Pendiente lineal $(\mathrm{kN} / \mathrm{mm})$} \\
\hline & & Experimental & Numérica & \begin{tabular}{|l} 
Diferencia \\
relativa (\%)
\end{tabular} & Experimental & Numérica & $\begin{array}{l}\text { Diferencia } \\
\text { relativa (\%) }\end{array}$ \\
\hline \multirow{3}{*}{$\begin{array}{l}\text { Alternativa } 1 \\
\text { Esp. } 7.5 \mathrm{~mm} \\
\text { Tornillo M14 }\end{array}$} & P1 & 75.0 & 74.8 & 0.3 & 89.3 & 71.6 & 19.8 \\
\hline & P2 & 71.9 & 73.7 & 2.5 & 76.1 & 74.8 & 1.7 \\
\hline & P3 & 79.9 & 73.1 & 8.5 & 170.7 & 77.4 & 54.7 \\
\hline \multirow{3}{*}{$\begin{array}{l}\text { Alternativa } 2 \\
\text { Esp. } 7.5 \mathrm{~mm} \\
\text { Espárrago } 3 / 4\end{array}$} & P1 & 108.0 & 118.5 & 9.7 & 201.1 & 215.5 & 7.1 \\
\hline & P2 & 104.1 & 118.3 & 13.6 & 239.9 & 215.1 & 10.3 \\
\hline & P3 & 107.8 & 116.8 & 8.3 & 127.4 & 212.4 & 66.7 \\
\hline
\end{tabular}

\section{ANÁLISIS DE ALTERNATIVAS}

En esta sección se realiza el análisis de las dos alternativas de diseño del sistema de sujeción, considerando condiciones reales de operación y la variación del espesor de la placa antidesgaste, que es el parámetro de interés. La consideración de las condiciones reales de operación está dada por: 1) los modelos contemplan todos los componentes del sistema de sujeción (ensamblajes completos); 2) cargas de operación (pretensión de la unión atornillada, presión y fuerza de fricción producidas por el material granulado sobre la placa, peso propio). Se evalúan cinco espesores remanentes de la placa antidesgaste: $15.0 \mathrm{~mm}, 13.1 \mathrm{~mm}, 11.3 \mathrm{~mm}$, $9.4 \mathrm{~mm}$ y $7.5 \mathrm{~mm}$; los que equivalen a los grados de desgaste: $60 \%, 65 \%, 70 \%, 75 \%$ y $80 \%$. La finalidad de estos análisis es determinar el espesor remanente mínimo de la placa antidesgaste con el que cada alternativa podría trabajar de manera segura. De esta manera se puede determinar en qué medida se logra aumentar la vida útil de la placa, en comparación con el diseño actual. Para estos análisis se usan los modelos constitutivos y criterios de falla que fueron descritos y validados en la sección previa.

\section{Consideraciones para el análisis de las alternativas}

Siguiendo las recomendaciones de Wu (2012), los componentes de la unión atornillada de los sistemas de sujeción de ambas alternativas (tornillo o espárrago, arandelas y tuerca) son modelados como una sola pieza, tal como se muestra en la Figura 13. El material asignado a esta pieza es ASTM A325 Tipo I, que es el material del elemento principal (tornillo y del espárrago). Por otro lado, en el caso específico de la alternativa 1, además de los componentes de la unión atornillada, se añade la tapa de ajuste, la cual permite realizar el apriete de la unión (Figura 13a). El material de la tapa de ajuste es SAE 1045 y se emplea un modelo elasto-plástico bilineal para definir su comportamiento. En los análisis de las alternativas las cargas se aplican en dos pasos, lo que responde a la secuencia real que se practica durante el montaje de las placas antidesgaste. En el primer paso se aplica la fuerza de pretensión de la unión atornillada, que representa el momento del montaje de la placa, y simultáneamente se activa la aceleración de gravedad (para considerar el peso propio). Luego, en el segundo paso, se aplica la presión y la fuerza de fricción. La fuerza de pretensión se configura de tal manera que, en el segundo paso de carga, se bloquea el valor de desplazamiento resultante de la fuerza de pretensión. Esto posibilita captar adecuadamente los efectos de la presión y de la fuerza de fricción que se aplican posteriormente, las cuales puedan aliviar o aumentar la tensión en el tornillo. Para este fin se utiliza el comando SLOAD del software ANSYS Mechanical (ANSYS, 2018). 


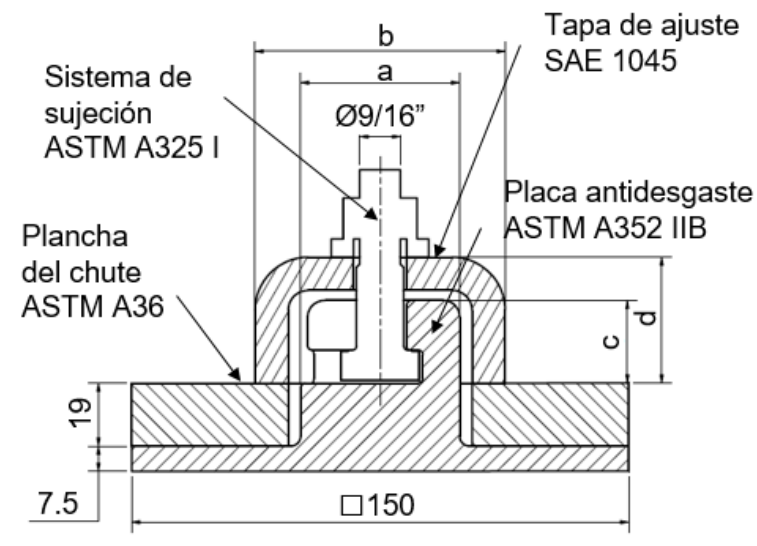

a)

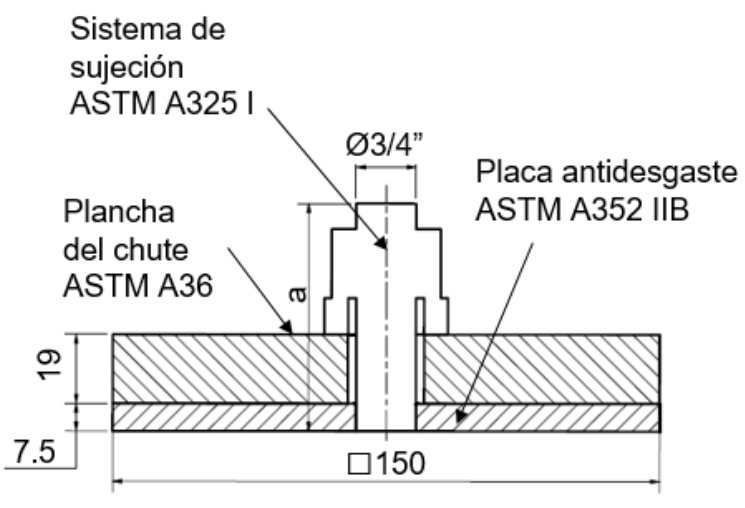

b)
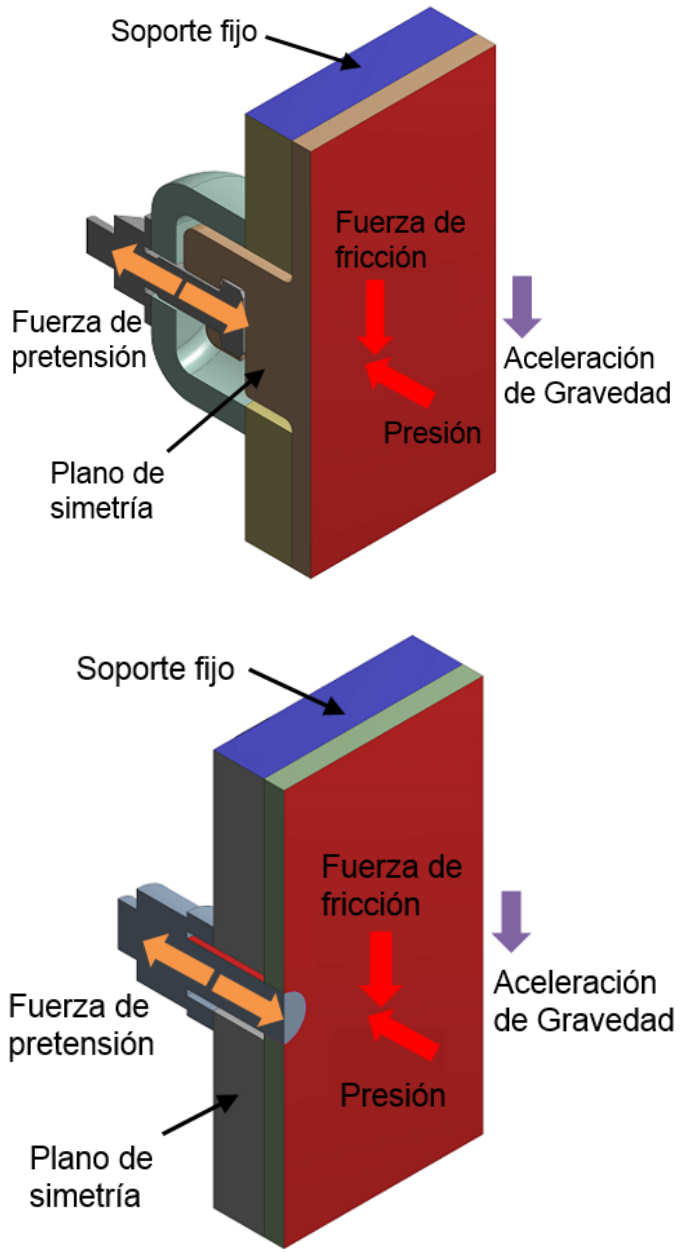

Fig. 13: Geometría y condiciones de borde de los ensambles completos, a) alternativa 1, b) alternativa 2

\section{Cálculo de las cargas de operación}

La fuerza de pretensión de las uniones atornilladas se determina según la norma ASTM A325 (ASTM A325 - 10, 2010) y se muestran en la Tabla 2 para cada alternativa. Por otro lado, para calcular la presión y la fuerza de fricción, se considera que el volumen y la forma cónica del material almacenado sobre el chute (stockpile) permanecen invariables en el tiempo y, por ende, dichas fuerzas son también constantes. El cálculo se realiza según la norma AS 3774 (AS 3774, 1996), la cual establece que la presión tiene una distribución parabólica, según la ecuación (1), alcanzando su valor máximo en las placas ubicadas en la parte inferior del chute.

$$
P v_{x}=1.25\left[\rho g\left(\frac{H}{3}\right)\right]\left[1-1.6\left(\frac{d_{x}}{D}\right)^{2}\right]
$$

Empleando la expresión (1) y considerando las dimensiones del stockpile (altura del cono $\mathrm{H}=70 \mathrm{~m}$; diámetro de la base del cono $D=140 \mathrm{~m}$; posición diametral del chute $\mathrm{d}_{\mathrm{x}}=64.5 \mathrm{~m}$ ) y la densidad del material granulado $\rho=1.9 \mathrm{Tn} / \mathrm{m}^{3}$, se obtiene una presión (carga normal distribuida) sobre la placa antidesgaste igual a $0.36 \mathrm{MPa}$. Asimismo, considerando un coeficiente de fricción igual a 0.70 entre el material granulado y la placa (Schellart, 2000), se obtiene la fuerza de fricción distribuida igual a $0.25 \mathrm{MPa}$. A continuación, la Tabla 5 presenta un resumen de las cargas aplicadas para el análisis.

Tabla 5: Cargas de pretensión y operación

\begin{tabular}{|l|l|l|l|l|}
\hline \multirow{2}{*}{ Tipo de carga } & $\begin{array}{l}\text { Área de } \\
\text { aplicación }\left(\mathrm{m}^{2}\right)\end{array}$ & $\begin{array}{l}\text { Fuerza distribuida } \\
(\mathrm{MPa})\end{array}$ & $\begin{array}{l}\text { Fuerza resultante } \\
(\mathrm{kN})\end{array}$ \\
\hline $\begin{array}{l}\text { Fuerza de } \\
\text { pretensión }\end{array}$ & Alternativa 1 & - & - & 61.4 \\
\cline { 2 - 5 } & Alternativa 2 & - & - & 112.4 \\
\hline Presión & Alternativa 1 y 2 & 0.0225 & 0.36 & 8.2 \\
\hline Fuerza de fricción & Alternativa 1 y 2 & 0.0225 & 0.25 & 5.7 \\
\hline
\end{tabular}




\section{RESULTADOS Y DISCUSIÓN}

Los resultados del análisis paramétrico, en función del espesor remanente de la placa antidesgaste, se muestran en la Figura 14 para ambas alternativas. La gráfica muestra una relación prácticamente lineal entre el FS y el espesor remanente de la placa antidesgaste, en forma de dos segmentos paralelos, donde el segmento correspondiente a la alternativa 1 (color rojo) se encuentra desplazado por encima del segmento correspondiente a la alternativa 2 (color azul). Tomando como referencia un FS de 1.5, se observa que la alternativa 1 podría operar con un espesor remanente de $7.5 \mathrm{~mm}$, equivalente a un desgaste del $80 \%$. En cambio, para el mismo FS, la alternativa 2 operaría con un espesor remanente de $12 \mathrm{~mm}$, equivalente a un desgaste del $68 \%$. Se puede afirmar que ambas alternativas presentan un mejor desempeño que el diseño actual del sistema de sujeción, toda vez que las placas antidesgaste actuales se retiran de funcionamiento cuando tienen un desgaste de aproximadamente el $60 \%$.

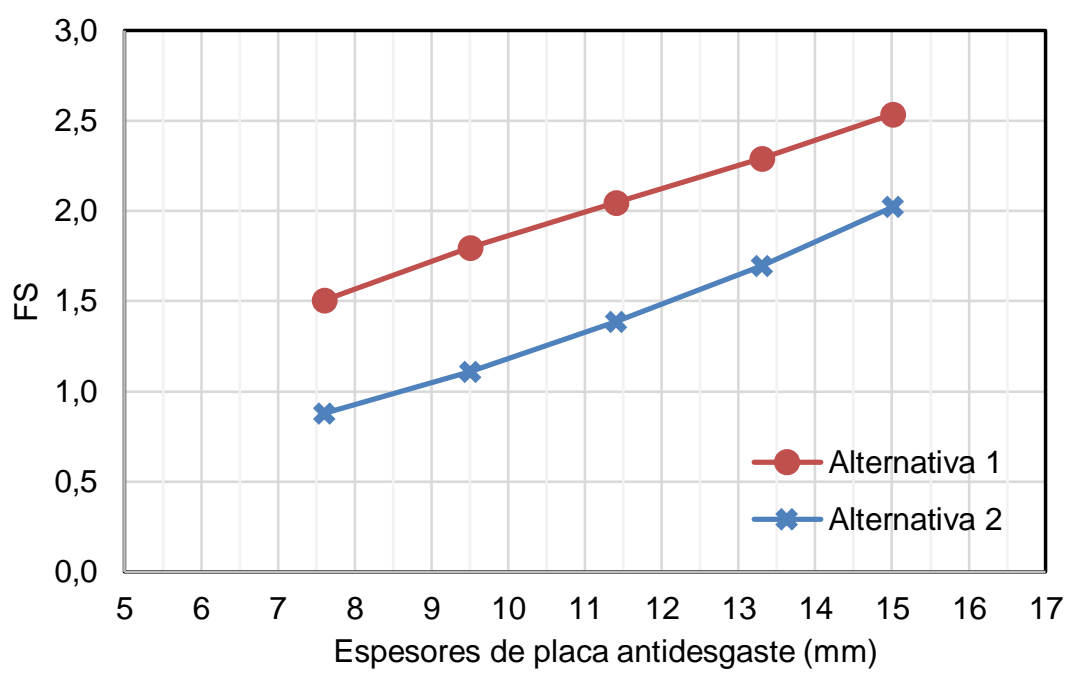

Fig. 14: Factor de seguridad en función del espesor remanente de la placa antidesgaste alternativas 1 y 2

\section{CONCLUSIONES}

El desempeño del sistema de sujeción de las placas antidesgaste, expresado a través de su FS, depende linealmente del espesor remanente de la placa antidesgaste. A medida que disminuye el espesor remanente de la placa, disminuye también el FS. Tomando en consideración los valores del FS, obtenidos para las dos alternativas de diseño propuestas en este trabajo, se puede afirmar que ambas alternativas presentan un desempeño mejorado frente al actual sistema de sujeción. Desde el punto de vista técnico, la alternativa 1 resulta ser la mejor opción entre las dos propuestas, ya que esta aprovecha en un $20 \%$ adicional el espesor de la placa antidesgaste, frente al actual diseño, sin comprometer su integridad estructural. Corresponde al fabricante tomar la decisión definitiva, quien debe evaluar la factibilidad de los procesos de fabricación de ambas alternativas y su correspondiente impacto económico, en función de sus propias tecnologías.

De acuerdo con los resultados obtenidos, el modelo constitutivo Cast Iron resulta adecuado para modelar el material frágil de la placa antidesgaste, en conjunto con el criterio de falla de Mohr Coulomb. De igual manera, resulta adecuado utilizar el modelo constitutivo elasto-plástico bilineal para modelar los materiales dúctiles del sistema de sujeción, en conjunto con el criterio de falla de Von Mises. Asimismo, el modelo simplificado de unión atornillada utilizado en el presente trabajo resulta ser conveniente y adecuado para efectos de captar el comportamiento mecánico real del sistema de sujeción.

El estudio experimental ha sido una etapa necesaria dentro de la metodología de trabajo para validar los modelos numéricos de los sistemas de sujeción. Además, ha permitido comprender el comportamiento físico de los componentes objeto de estudio, así como apreciar los modos de falla característicos. Gracias a la comparación entre los resultados experimentales y numéricos, se han obtenido modelos numéricos capaces de representar adecuadamente el comportamiento de los sistemas de sujeción.

\section{AGRADECIMIENTOS}

Los autores agradecen a los colegas de la empresa Fundición Ferrosa S.A.C., quienes propusieron el problema inicial para la investigación que sienta las bases del presente trabajo. Asimismo, se agradece a la empresa por la manufactura de las probetas y por brindar información técnica sobre la placa antidesgaste actual y de las propuestas de diseño de los sistemas de sujeción (dimensiones, materiales, y propiedades 
mecánicas). Además, se agradece al Laboratorio de Materiales de la Pontificia Universidad Católica del Perú por realizar los ensayos experimentales. Finalmente, se agradece a Innóvate Perú por el financiamiento otorgado para realizar la investigación.

\section{REFERENCIAS}

Ali, Y., Garcia-Mendoza, C.D. y Gates, J.D., Effects of 'Impact' and Abrasive Particle Size on the Performance of White Cast Irons Relative to Low-Alloy Steels in Laboratory Ball Mills, https://doi.org/10.1016/j.wear.2019.01.048, Wear, 426-427, 83-100 (2019)

ANSYS Academic Research, Release 19.0, Help System, ANSYS, Inc. (2018)

AS 3774-1996, Loads on Bulk Solids Containers, Standards Australia, Homebush, NSW, Australia, (1996)

ASTM A325-10, Standard Specification for Structural Bolts, Steel, Heat Treated, 120/105 ksi Minimum Tensile Strength, ASTM International, West Conshohocken, PA, USA, (2010)

Davies, B., United States Patent N. US 7877948 B2, Retrieved from https://bit.ly/37nTScJ, (2011)

Elston, F., International Publication Number WO 2015/196247 A1, Retrieved from https://bit.ly/2D46nwn, (2015)

Hwang, H. Y., Bolted Joint Torque Setting Using Numerical Simulation and Experiments, https://doi.org/10.1007/s12206013-0317-2, Journal of Mechanical Science and Technology, 27(5), 1361-1371 (2013)

Mac, B. J., Practical Stress Analysis with Finite Elements, $2^{a}$ edición. Glasvening Publishing, Dublin, Ireland (2011)

Park, J., Park, S.Y. y otros cuatro autores; Numerical Analysis of Torsional Behavior of Ultra-High Performance Fiber Reinforced Concrete, International Journal of Advanced Research in Science Engineering and Technology, ISSN: 2350$0.328,4(8), 4443-4453(2017)$

Schellart, W. P., Shear Test Results for Cohesion and Friction Coefficients for Different Granular Materials: Scaling Implications for their Usage in Analogue Modelling, https://doi.org/10.1016/S0040-1951(00)00111-6, Tectonophysics, 324(1-2), 1-16 (2000)

Vadiraj, A., Kamaraj, M. y Sreenivasan, V. S., Effect of Solid Lubricants on Friction and Wear Behavior of Alloyed Gray Cast Iron, https://doi.org/10.1007/s12046-012-0061-9, Sadhana - Academy Proceedings in Engineering Sciences, 37(5), 569-577 (2012)

Valtonen K., Ojala, N. y otros dos autores, Comparison of Various High-Stress Wear Conditions and Wear Performance of Martensitic Steels, https://doi.org/10.1016/j.wear.2018.12.006, Wear, 426-427, 3-13 (2019)

Wu, Z., Zhang, S. y Jiang S., Simulation of Tensile Bolts in Finite Element Modeling of Semi-Rigid Beam-To-Column Connections, https://doi.org/10.1007/s13296-012-3004-8, International Journal of Steel Structures, 12(3), 339-350 (2012)

Xu, Q. J., Chen, Y. Y. y otros cuatro autores, Sliding Friction Properties of Austenite-and Martensite-Based White Cast Iron containing 8.5\% Chromium, https://doi.org/10.1007/s10853-010-4697-8, Journal of Materials Science, 45(22), 61086114 (2010)

Yu, Q., Zhou, H. y Wang, L., Finite Element Analysis of Relationship between Tightening Torque and Initial Load of Bolted Connections, https://doi.org/10.1177/1687814015588477, Advances in Mechanical Engineering, 7(5), 1-8 (2015) 